\title{
25 Research Soure \\ Knowledge of End-of-life Wishes by Physicians and Caregivers in Cancer Patients
}

Jose A Calvache

Universidad del Cauca

Socorro Moreno

Pontificia Universidad Javeriana

Gillian Prue

Queen's University Belfast

Joanne Reid ( $\sim$ j.reid@qub.ac.uk)

Queen's University Belfast

Sam Ahmedzai

University of Sheffield, Royal Hallamshire Hospital

Angelica Arango-Gutierrez

Pontificia Universidad Javeriana

Liliana Ardila

National Cancer Institute

Lucia I Arroyo

MSc programme Public Health, Pontificia Universidad Javeriana Cali, Universidad de Cauca

Esther de Vries

Pontificia Universidad Javeriana

\section{Research Article}

Keywords: End of life, Cancer, Communication, Advance Directives, Decision Making

Posted Date: May 5th, 2021

DOI: https://doi.org/10.21203/rs.3.rs-493247/v1

License: (c) (1) This work is licensed under a Creative Commons Attribution 4.0 International License.

Read Full License

Version of Record: A version of this preprint was published at BMC Palliative Care on September 10th, 2021. See the published version at https://doi.org/10.1186/s12904-021-00823-1. 


\section{Abstract}

Objectives: To describe communication regarding cancer patient's end-of-life (EoL) wishes by physicians and caregivers.

Methods: An online questionnaire and telephone-based surveys were performed with physicians and caregivers respectively in three teaching hospitals in Colombia who had been involved in the EoL care of cancer patients.

Results: For 138 deceased patients we obtained responses from physicians and caregivers. In $32 \%$ physicians reported they spoke to the caregiver and in $17 \%$ with the patient regarding EoL decisions. In most cases with absence of a conversation, physicians indicated the treatment option was "clearly the best for the patient" or that it was "not necessary to discuss treatment with the patient".

Twenty-six percent of the caregivers indicated that someone from the medical team spoke with the patient about treatment, and in $67 \%$ who had a conversation, caregivers felt that the provided information was unclear or incomplete. Physicians and caregivers were unaware if the patient had any advance care directive (ACD) in $65 \%$ and $51 \%$ of cases, respectively, with a very low absolute agreement (34\%).

Conclusion: There is a lack of open conversations regarding EoL in patients with advanced cancer with their physicians and caregivers in Colombia. Communication strategies are urgently needed.

\section{Background}

Colombia's population ages rapidly, mortality patterns shift from being dominated by unnatural causes and communicable diseases towards dominance by chronic diseases [1]. The growing number of patients with chronic diseases has led to a growing consciousness in society and the medical community that end-of-life (EoL) care for patients with chronic conditions may involve complex decision-making processes [2].

In Colombia, palliative care was regulated and discussions regarding actively ending life have resulted in euthanasia regulation $[3,4]$. It is unknown whether Colombian patients actively communicate with their physicians and caregivers regarding their wishes and needs. Previous studies indicate substantial levels of intensive cancer treatments very close to the EoL [5], physicians report little communication [6] and advance care directives (ACD) are not frequently formulated formally (personal communications). In this study, we aimed to describe communication regarding cancer patient's wishes at the EoL by their treating physicians and caregivers.

\section{Methods}

An online questionnaire was used for the physicians and telephone-based surveys were performed with caregivers of patients who attend one of three participating teaching hospitals between May 2019 and 
May 2020: Instituto Nacional de Cancerología Bogotá (INC), Hospital Universitario San Ignacio Bogotá (HUSI), and Hospital Universitario San José Popayán (HUSJ). All three have specialized oncology services and palliative care teams. The first two are in Bogota, the INC being a specialized and public cancer referral hospital, attending over 7000 new patients per year, and HUSI being a non-profit, tertiary hospital. HUSJ is a public hospital in a Colombian province in the city of Popayán, attending the urban population ( $>300,000$ inhabitants) and a largely rural area, including several indigenous populations.

Nurses and physicians identified oncological patients, notified the research team when a cancer patient with a life expectancy of three months or less was seen. When these patients deceased, a researcher obtained basic information and invited the attending physicians who had been involved in the patient's EoL care to participate within the study. Caregivers of the deceased patients, identified from the medical records, were contacted by telephone, received information about the study and were invited to participate.

The physicians received a patient code and a link to the online questionnaire, which focused on the characteristics of the EoL decision-making that preceded the death of the patient involved, details are provided elsewhere (see additional file 1), [7-9]. When a decision had a potential life-shortening effect, physicians were asked if they had spoken to the patient and/or caregivers regarding this potential effect of the treatment decision. Physicians were also asked if the patient had an ACD.

Among the caregivers, the telephone survey measured the level of involvement in the care of the patient, demographic information, and structured questions regarding the type of care received, information received by the healthcare providers, conversations with the healthcare providers, and if the patient had an ACD or had expressed wishes or preferences regarding treatment and other issues regarding the EoL (see additional file 2).

Analyses were conducted using SPSS Version 25 (IBM). General characteristics were summarized using absolute frequencies, proportions, means, medians, and interquartile ranges (IQR). Absolute agreement (or proportion of overall agreement) was calculated by adding the number of affirmative and negative responses in which physicians and caregivers agreed, divided by the total number of ratings [10].

\section{Results}

We obtained response from 261 physicians and 176 caregivers of 341 identified patients (response rate $76.5 \%$ and $51.6 \%$ respectively); this led to 138 cases were both physicians and caregivers of the same patient participated. Most physicians ( $95 \%)$ confirmed they were the treating physicians. All caregivers were family members: partner of the deceased $(n=26,19 \%)$, parents $(n=6,4 \%)$, siblings $(n=23,17 \%)$, children $(n=72,52 \%)$, and other family members $(n=14,10 \%)$. Half of the caregivers had lived with the patient; most had an educational level of high school or lower $(66 \%) ; 91 \%$ described themselves as "very involved in the patient care". 
The median time between death and the physicians' completing the questionnaire was nine days (IQR 620 days). The median time between death and the interview with caregivers was 23.8 weeks (IQR 22.127 weeks).

Table 1 presents the distribution of patients' general characteristics - mean age was 61.5 years (SD 15.3), half were female, and most had died in hospital (86\%).

Table 1

General characteristics of patients

\begin{tabular}{|c|c|c|c|c|}
\hline & $\begin{array}{l}\text { Total } n=138 \\
n(\%)\end{array}$ & $\begin{array}{l}\text { HUSI* n = } 43 \\
n(\%)\end{array}$ & $\begin{array}{l}\text { INC* n = } 83 \\
n(\%)\end{array}$ & $\begin{array}{l}\text { HUSJ* } n=12 \\
n(\%)\end{array}$ \\
\hline \multirow{2}{*}{$\begin{array}{l}\text { Age (mean } \pm \text { SD, median } \\
{[[\mathrm{QR}])}\end{array}$} & $61.5 \pm 15.3$ & $64.7 \pm 15.3$ & $58.9 \pm 14.5$ & $67.9 \pm 18$ \\
\hline & $64[51-73]$ & $\begin{array}{l}67.5[60.5- \\
75.5]\end{array}$ & $59[50-69]$ & $70[50.7-85.7]$ \\
\hline Female gender & $72(48)$ & $15(35)$ & $49(59)$ & $8(67)$ \\
\hline \multirow{3}{*}{$\begin{array}{l}\text { Top three cancer } \\
\text { diagnosis }\end{array}$} & Gastric 26 (19) & Gastric 8 (19) & Gastric 15 (18) & Gastric 3 (25) \\
\hline & $\begin{array}{l}\text { Colorectal } 14 \\
\text { (10) }\end{array}$ & $\begin{array}{l}\text { Colorectal } 5 \\
(12)\end{array}$ & $\begin{array}{l}\text { Colorectal } 9 \\
\text { (11) }\end{array}$ & \multirow{2}{*}{$\begin{array}{l}\text { Breast } 2 \text { (17) } \\
\text { Cervical } 2 \text { (17) }\end{array}$} \\
\hline & Breast 13 (9) & Breast 3 (7) & Breast 8 (10) & \\
\hline \multirow[t]{3}{*}{ Health care insurance } & $\begin{array}{l}\text { Contributive } 70 \\
\text { (51) }\end{array}$ & $\begin{array}{l}\text { Contributive } 42 \\
\text { (98) }\end{array}$ & $\begin{array}{l}\text { Contributive } 24 \\
\text { (29) }\end{array}$ & $\begin{array}{l}\text { Contributive } 4 \\
\text { (33) }\end{array}$ \\
\hline & $\begin{array}{l}\text { Subsidized } 56 \\
(41)\end{array}$ & $\begin{array}{l}\text { Subsidized } 0 \\
\text { (0) }\end{array}$ & $\begin{array}{l}\text { Subsidized } 49 \\
\text { (59) }\end{array}$ & $\begin{array}{l}\text { Subsidized } 7 \\
\text { (58) }\end{array}$ \\
\hline & Other 12 (8) & Other $1(2)$ & Other $10(12)$ & Other 1 (8) \\
\hline
\end{tabular}

Physicians and caregivers agreed in most cases that the patient had received drugs to control pain and other severe symptoms (physicians: $n=123,89 \%$; caregivers $n=125,91 \%$ - absolute agreement physicians - caregivers $83 \%$ (Table 2 ).

Table 2. Affirmative responses by physicians and caregivers and agreement between them regarding endof-life questions 


\begin{tabular}{|llll|}
\hline Question & $\begin{array}{l}\text { Affirmative } \\
\text { response by } \\
\text { physicians } \\
\text { n (\%) }\end{array}$ & $\begin{array}{l}\text { Affirmative } \\
\text { answer by } \\
\text { caregivers } \\
\mathbf{n}(\%)\end{array}$ & $\begin{array}{l}\text { Proportion of } \\
\text { absolute agreement } \\
\text { (\%)* }\end{array}$ \\
\hline $\begin{array}{l}\text { Did the patient receive palliative } \\
\text { care? }\end{array}$ & $120(87 \%)$ & $122(88 \%)$ & $78 \%$ \\
\hline $\begin{array}{l}\text { Did the patient receive treatment } \\
\text { for pain or other symptoms? }\end{array}$ & $123(89 \%)$ & $125(91 \%)$ & $83 \%$ \\
\hline $\begin{array}{l}\text { Did the patient have any explicit } \\
\text { advance care directive? }\end{array}$ & $8(6 \%)$ & $36(26 \%)$ & $34 \%$ \\
\hline $\begin{array}{l}\text { *Absolute agreement was calculated by adding the number of affirmative and negative responses in } \\
\text { which physicians and caregivers agree, divided by the total number of ratings [10]. }\end{array}$ \\
\hline
\end{tabular}

In 44 cases (32\%), physicians reported that they spoke to the caregiver regarding the potential effect of hastening the patient's death because of the decisions made in the last phase of life. In 11 of those cases (25\%), not postponing the patient's death was requested by caregiver. In 24 cases (17\%), physicians responded that they spoke directly with the patient about the potential hastening of their death because of the intervention. Three patients requested to hasten their EoL, but their requests were not fulfilled. Physicians indicated they agreed regarding the non-use of resuscitation manoeuvres at the EoL with the patient in 26 cases, with patients' family members in 80 , and other caregivers in 14 cases. There was absence of agreement on this matter in 9 cases.

In the absence of a conversation about interventions at the EoL, physicians indicated mostly they had not discussed this because the treatment option was "clearly the best for the patient" $(n=30,22 \%)$ or that it was "not necessary to discuss treatment with the patient" $(n=18,13 \%)$.

Few caregivers $(n=36,26 \%)$ indicated that someone from the medical team spoke with the patient about medical treatment preferences during the last week of life, (vs. $n=71,51 \%)$ no conversation, $12(9 \%)$ did not know). In 23 of the 36 patients who had a conversation (67\%), caregivers felt that the information provided by the medical team was unclear or incomplete. Caregivers perceived those medical interventions had prolonged patients' life in 46 cases, and in 32 of these, the caregiver felt that this prolongation had increased the patient's suffering.

Physicians outlined eight patients had ACD (6\%), from which three were explicit. For most cases $(n=90$, $65 \%$ ), physicians did not know if the patient had any ACD (no answer provided for 40 cases). Most caregivers $(n=71,51 \%)$ indicated that their relative had no ACD or explicit requests, 3 did not know and in 36 cases, the caregivers indicated that the patient did have requests (26\%) (10 formally, 26 informally formulated). The proportion of absolute agreement on whether the patient had an ACD was very low (34\%, Table 2). 


\section{Discussion}

Our results show a lack of communication and awareness among physicians and even caregivers regarding the patient's EoL preferences. Our study design cannot elucidate the reasons behind this phenomenon, but it is likely that neither physicians nor caregivers asked the patient regarding preferences, wishes and fears regarding the EoL [2].

The low agreement between physicians and caregivers regarding the existence of ACD indicate that, even though a minority of terminally ill cancer patients had expressed such directives, the communication of those directives was very poor - often either a physician or a caregiver (or perhaps both) were not aware of the directive.

The increase in technological possibilities of treatment and care has led, in many countries, to regulation regarding patients' rights to refuse treatment or co-decide whether life-sustaining therapies will be used in their care [11]. As palliative and EoL care aim to relieve suffering and optimize quality of life, it is important to know if and how patients suffers and what matters to them. Shared decision making requires effective and empathic communication between formal and informal caregivers and the patients $[2,12]$. It has been shown that patients with advanced cancer prefer early and open communication about EoL topics [13].

Our results show a general lack of such conversations: physicians demonstrate a generally paternalistic attitude, where they could decide on what would be best for the patients, which is commonly noted in similar scenarios [14]. Caregivers were often unaware if patients had an ACD and often felt that either they or the patients were not optimally heard, or that their preferences were not taken into account. There are several existential and material costs associated with poor communication in cancer care that should be considered and prioritized in any agenda [15]. Among others, poor communication leads to significant misunderstandings by patients and caregivers regarding the nature and seriousness of the disease, treatment, and prognosis.

Study limitations include the potential of selection bias: physicians may have been more prone to decline participation for patients who died outside of hospital, as they would be less informed about those patients' EoL issues. Similarly, caregivers' own experiences may have influenced their decision to participate. Phone surveys were considered necessary because a substantial proportion of the Colombian population is functionally illiterate. It was impossible to reach some caregivers, either because of erroneous telephone numbers $(7 \%)$ or because they never answered the telephone $(22 \%)-91 \%$ of caregivers who were reached decided to participate. Finally, absolute agreement of responses between physicians and caregivers is informative and useful, but it does not distinguish between agreement on positive ratings and agreement on negative ratings.

\section{Conclusions}


Our results suggest a lack of open conversations regarding EoL matters in patients with advanced cancer with their physicians and caregivers. Training in and implementation of effective communication strategies regarding EoL care for patients, physicians, and caregivers [2] are urgently needed in Colombia.

\section{List Of Abbreviations}

EoL end-of-life

ACD advance care directive

INC Instituto Nacional de Cancerología Bogotá

HUSI Hospital Universitario San Ignacio Bogotá

HUSJ Hospital Universitario San José Popayán

IQR interquartile range

\section{Declarations}

ETHICS APPROVAL AND CONSENT TO PARTICIPATE. The study protocol was approved by the research ethics committees at Pontificia Universidad Javeriana (number FM-CIE-0086-17) and NCI (Instituto Nacional de Cancerología, number INT-OFI-03581-2019). The physicians answered the questionnaire anonymously. No information on specialization, age, sex, or years or experience of the participating physician was collected. Caregivers were contacted by phone to ask for their consent to participate in the study and explained that their data would be managed confidentially, anonymized analysis of their responses was guaranteed. The case number of the deceased patient were used to link the physician and caregiver information to guarantee that the agreement analysis occurred at the individual level.

CONSENT FOR PUBLICATION. Not required.

AVAILABILITY OF DATA AND MATERIALS: The datasets used and/or analysed during the current study are available from the corresponding author on reasonable request.

COMPETING INTERESTS. None declared.

FUNDING. This work was supported by Minciencias, in the framework of the "777-2017 Convocatoria para proyectos de ciencia, tecnología e innovación en Salud 2017", project CT-826-2018 - Decisiones médicas al final de la vida en pacientes oncológicos en Colombia". Minciencias (Colombian government research funding body) had no role in the design of the study and collection, analysis, and interpretation of data of in writing the manuscript.

AUTHORS' CONTRIBUTIONS: EdV, SM, JAC conceptualized the study; EdV, SM, JAC developed the methodology and analytical plan. AA, LA, LIA undertook data collection and preliminary analysis assisted 
by JAC, EdV. GP, JR, SA contributed to final analysis and interpretation of the data. EdV, JAC, GP, JR drafted the manuscript, all others revised. All authors have read and approved the final manuscript.

ACKNOWLEDGEMENTS. We are very grateful for the participation of all anonymous physicians who took the time to answer the questionnaires and caregivers to answer the phone-based surveys. We also thank the following people who have been closely involved in the design of the project and made this work possible: Carlos Gómez-Restrepo, Nelcy Rodríguez, Carolina Wiesner, Fabián Leal, Raúl Murillo, Fritz Gempeler and Eduardo Díaz.

\section{References}

1. Sleeman KE, de Brito M, Etkind S, Nkhoma K, Guo P, Higginson IJ, et al. The escalating global burden of serious health-related suffering: projections to 2060 by world regions, age groups, and health conditions. Lancet Glob Health 2019;7:e883-92. https://doi.org/10.1016/S2214-109X(19)30172-X.

2. Nagelschmidt K, Leppin N, Seifart C, Rief W, von Blanckenburg P. Systematic mixed-method review of barriers to end-of-life communication in the family context. BMJ Support Palliat Care 2020. https://doi.org/10.1136/bmjspcare-2020-002219.

3. Calvache J, Gil F, De Vries E. How many people need palliative care for cancer and non-cancer diseases in a middle-income country? Analysis of mortality data. Colombian Journal of Anesthesiology 2020;48:e924. http://dx.doi.org/10.1097/CJ9.0000000000000159.

4. Peña AJ, Figueroa KL. Morir dignamente: una visión desde el derecho colombiano. 1ra edicion. Popayan: Universidad del Cauca; 2020.

5. Cuadrado Franco DM, Gempeler F, Torregrosa Almonacid L. Tratamientos no proporcionados al final de la vida en pacientes fallecidos en un hospital universitario de 4 nivel. Pontificia Universidad Javeriana, 2019.

6. Luna-Meza A, Godoy-Casasbuenas N, Calvache JA, Diaz E, Gempeler F, Morales O, et al. Decision making in the end-of-life care of patients who are terminally ill with cancer - a qualitative descriptive study with a phenomenological approach from the experience of healthcare workers. Research Square (Preprint) 2021. https://doi.org/10.21203/rs.3.rs-155936/v1.

7. van der Heide A, Onwuteaka-Philipsen BD, Rurup ML, Buiting HM, van Delden JJM, Hanssen-de Wolf $\mathrm{JE}$, et al. End-of-life practices in the Netherlands under the Euthanasia Act. N Engl J Med 2007;356:1957-65. https://doi.org/10.1056/NEJMsa071143.

8. Sterfgevallenonderzoek 2010; Euthanasie en andere medische beslissingen rond het levenseinde ZonMw Digitale Publicaties n.d. https://publicaties.zonmw.nl/sterfgevallenonderzoek-2010euthanasie-en-andere-medische-beslissingen-rond-het-levenseinde/ (accessed March 15, 2021).

9. De Vries E, Leal F, van der Heide A, Gempeler F, Murillo R, Morales O, et al. Medical decisions concerning the end of life for cancer patients in three Colombian hospitals - a survey study. Research Square (Preprint) 2021. https://doi.org/10.21203/rs.3.rs-288762/v1. 
10. Uebersax J. Raw Agreement Indices. Raw Agreement Indices n.d. http://www.johnuebersax.com/stat/raw.htm (accessed March 16, 2021).

11. Towers B. The impact of the California Natural Death Act. J Med Ethics 1978;4:96-8. https://doi.org/10.1136/jme.4.2.96.

12. Frank RK. Shared decision making and its role in end of life care. $\mathrm{Br} J$ Nurs 2009;18:612-8. https://doi.org/10.12968/bjon.2009.18.10.42466.

13. Brighton LJ, Bristowe K. Communication in palliative care: talking about the end of life, before the end of life. Postgrad Med J 2016;92:466-70. https://doi.org/10.1136/postgradmedj-2015-133368.

14. Sandman L, Munthe C. Shared decision making, paternalism and patient choice. Health Care Anal 2010;18:60-84. https://doi.org/10.1007/s10728-008-0108-6.

15. Thorne SE, Bultz BD, Baile WF, SCRN Communication Team. Is there a cost to poor communication in cancer care?: a critical review of the literature. Psychooncology 2005;14:875-84; discussion 885886. https://doi.org/10.1002/pon.947.

\section{Supplementary Files}

This is a list of supplementary files associated with this preprint. Click to download.

- Additionalfile1.docx

- Additionalfile2.docx 